\title{
COMPASIÓN Y SIGNO EN LA POÉTICA DE DANTE*
}

Bruno Gelati**

\section{Premisa necesaria: el valor del signo}

En la obra de Dante Alighieri, tan imprevisible es su producción literaria que de verdadera poiesis se trata, en el sentido de re-creación de los acontecimientos que, si bien no cambian lo sucedido, dan el paso a una clave interpretativa que alienta, más allá del simple relato cronológico, el evento humano; la interpretación no es pura y autónoma subjetividad, siempre implica los factores libertad y unidad en el horizonte de la realidad experiencial.

El mismo Dante nos lo explica:

Para entender esto [el sentido de la escritura] es necesario saber que los escritos se pueden entender y se deben exponer principalmente en cuatro sentidos. Llámase el primero literal [y es éste aquel que no avanza más allá de la letra de las palabras convencionales, como sucede en las fábulas de los poetas. El segundo se llama alegórico] y éste es el que se esconde bajo el manto de esas fábulas, y consiste en una verdad oculta bajo un bello engaño. Como cuando dice Ovidio que Orfeo con su cítara amansaba las fieras y llevaba tras sí los árboles y las piedras,

* La compasión (o la passio del sentimiento humano) y el signo rationale et sensuale en el Canto de Paolo e Francesca de Dante, es el título original de este trabajo, abreviado por razones de espacio.

** Departamento Académico de Estudios Generales, ITAM. 
BRUNO GELATI

lo cual quiere significar que el hombre sabio con el instrumento de su voz amansaría y humillaría los corazones crueles y movería de acuerdo con su voluntad a los que carecen de la vida de la ciencia y del arte, pues los que no tienen vida racional alguna son casi como piedras.

El tercer sentido se llama moral, y éste es el que los lectores deben atentamente descubrir en los escritos, para utilidad suya y de sus discípulos, como puede observar en el Evangelio cuando Cristo subió al monte para transfigurarse, pues de los doce apóstoles llevó consigo tres, con lo cual puede entenderse, según el sentido moral, que en las cosas muy secretas debemos tener poca compañía.

El cuarto sentido se llama anagógico, es decir, sentido superior, y se tiene cuando se expone espiritualmente un escrito, el cual, aunque [sea verdadero] también en el sentido literal, por las cosas significadas significa realidades sublimes de la gloria eterna, como puede verse en aquel canto del profeta que dice que con la salida de Egipto del pueblo de Israel hízose Judea santa y libre. Pues, aunque sea verdadero cuanto la letra manifiesta, no es menos verdadero lo que espiritualmente se entiende, esto es, que al salir el alma del pecado se hace santa y libre en su propia potestad. Y al explicar estos sentidos, debe ir siempre delante el literal, por estar incluidos en éste todos los demás y porque sin él sería imposible e irracional entender los demás, y principalmente el alegórico. ${ }^{1}$

Tal es el mundo de sentido en el que Alighieri vive, convencido de que todo lo que adviene no encuentra satisfacción en su aspecto meramente empírico sino que se presenta y se completa bajo el aspecto del signo.

Dicho sea de paso, es preciso afirmar al respecto que hablar de la realidad como signum, incluye, para Dante, una específica representación que comprende el concepto de símbolo, metáfora, en el campo

${ }^{1}$ Dante, Convivio II, 1, 2-3-5-8. 
semántico, por ejemplo; o alegoría, perífasis, en el campo lógico. Elementos, todos que, como sabemos, hacen parte del cotidiano uso de la lingüística de la poíesis dantiana, que es indudablemente una de las más ricas y completas que existen.

Según Dante, el significado de signo es más extenso que el de símbolo, porque aquel comprende la realidad tal como ha sido dada, según lo que también afirma el poeta Rebora: El signo se abisma en donde es más verdadero, es decir en el misterio.

El signo se sigue, no sólo se mira; mientras que al símbolo no le es necesario in strict sensu este movimiento. Signo y realidad coinciden en una presencia real; quizá esto no sea necesario al símbolo, el cual puede pensarse no necesariamente en su aspecto real, en cuanto que él pertenece más al ámbito de la interpretación de la mente que a aquel de la experiencia vivida.

En efecto el signo alienta a la conciencia en relación con algo que la pone en la condición de poder afirmarse como un yo; es decir, el signo interroga al ser inteligente porque contiene totalmente el significado de la realidad que se manifiesta y se vela a nuestra mirada, bajo la exigencia de un re-envío: un aná.

Finalmente, signo y símbolo pueden tal vez coincidir en su aspecto lógico-semántico, pero no identificarse en su aspecto ontológico.

Afirma P. Ricoeur: Es cierto que los símbolos son signos; es decir que son expresiones que contienen y comunican un sentido, un mensaje; ese sentido se declara en un propósito significativo transmitido por la palabra. $^{2}$

Para el mundo medieval toda la realidad es signo: digito Dei; no en el sentido idealista -tener que trascenderla para poder entender- sino por la completa aceptación, de parte del espíritu del hombre, del entero perímetro en el que el signo se implica; es decir de su entorno o de su pondus, siendo que también los aspectos circunstanciales constituyen el significado del signo -el cual no puede dejar de lado ni un mínimo particular de lo que lo constituye, pues ello puede vehicular hacia una

${ }^{2}$ P. Ricoeur, Finitud y culpabilidad, 1991, Buenos Aires, Taurus, p. 178. 
significación más honda. Para Dante el uso mismo de la métrica induce a la comprensión del signo, incluso su ritmo es necesario al poeta para introducir al pathos que, desde el signo, puede re-crearse en la poesía. En efecto, a través del laberinto metafórico y alegórico del lenguaje, el simple relato asume su figura original y lo eleva a mímesis o participación de la realidad que se incluye en el signo como su forma de ser.

Puesto finalmente en un horizonte abierto y contemporáneamente velado, el signo a través de la poesía torna la realidad casi especular, al grado de crear una coincidencia entre lo que aparece como ficción poética y lo real -es decir la inventio-, facilitando la mirada de la mente hacia un centro o punto de fuga en el que se significa el mismo signo. En efecto, la trasparencia de la visión que la poesía ofrece parece proporcionar a la mente un conocimiento inmediato; en consecuencia la poesía simplifica la relación entre signo y significante siendo que en el signo, la poíesis siempre algo revela; finalmente, el signo es el que revela lo que el significante conlleva, el signo revela más de que lo que esconde. Revela a la mente de quien lo mira algo, mientras se deja penetrar por el acto de la razón.

Pero para el poeta no está permitida esta distracción de la mente con respecto al conocer, en cuanto que ésta reduciría el carácter del 'inventio' a favor de una especulación; y, sin embargo ni siquiera la pura ficción; en efecto, su ficción siempre va de la mano con la realidad; el desafío, si así podemos decir, de su visio atraviesa la inexorabilidad de los acaecimientos y los transhumaniza; es decir, transfigura lo que aparece y que el signo parece ocultar, para que se vuelva posible la comunicación de su significado.

Pero, en este transhumanizar, afirma Dante, no es posible significar con palabras [expresar plenamente con el acto del lenguaje] el acto de pensar a un grado superior de la naturaleza humana (Paraíso, III, 1, 43-75). Esta conciencia marca precisamente el límite o la frontera del signo que el poeta se encargará de develar.

Inicia, a partir de ello, un movimiento -el que podemos llamar ensimismamiento del acontecimiento de la poíesis, en su aspecto no sólo interpretativo, sino del endoso de lo sucedido, cargando en la propia 
experiencia poiética el valor del signo de una empresa ética-; empieza la extraña aventura del novidente poético, en cuanto que los ojos del poeta ven más todavía del ver y buscan en el hecho particular una morada, un ethos, una pertenencia en donde colocar la pieza singular en el polícromo mosaico del misterio del hombre y su destino.

Con esta finalidad se buscará, en estas breves consideraciones, poner en evidencia, a través de un ejercicio prevalentemente retórico-hermenéutico, la poíesis antropológica de nuestro autor, jugando principalmente entre los dos polos de su visio: el sentido de la preferencia manifestada por el misterio al hombre y a su historia y, por otra parte, la dramática realidad en la que se manifiesta su libertad: una incógnita permanente presente en la circunstancia, acompañada al mismo tiempo por un presentimiento de espera de algo diferente, siendo ello la dimensión humana que desgarra al rostro de lo desconocido su temeroso e inexorable fondo desesperanzador.

Quien, como nuestro autor, transfigura la existencia con su poesía, vuelve posible lo que se considera ya un evento imposible y abre al hombre un cosmos de posibilidades, es decir abre al sentido del misterio. Esta es principalmente la in-ventio del poeta, que no sólo está constituida por razones lógicas -al menos inmediatamente- y que se expresan, en el contexto abrumador de sus descripciones poéticas, tan atrevidas como los contrafuertes góticos y, al mismo tiempo, tan virilmente firmes como las bóvedas románicas.

En todo este mundo, la realidad es simil a las apostillas en las que están reverberadas, como en un espejo de agua, las imágenes de las que brota otro mundo dentro de este mismo: una catedral -o una morada- en el corazón del hombre, llena de símbolos que ofrecen a la mente la capacidad de rememorar la realidad como signo y empezar así el itinerario de la mente hacia el significado real de la experiencia. 
BRUNO GELATI

\section{El signo rationale et sensuale}

Entonces empezaremos nuestro camino considerando al Canto V del Infierno, conocido como el Canto de Paolo y Francesca, que presenta, como objeto de su contenido, la patología sensual y hasta lujuriosa de la condición humana y que ha vuelto famoso el relato de los dos amantes.

$\mathrm{Al}$ respecto, es preciso decir que la figura -en el sentido de imagen poética-que domina todo el campo de este Canto es, según lo sugiere el crítico María Corti, la siguiente: es Dante quien regresa al hombre y al cual puede comunicar algo en cuanto posee un signum;... el cual es juntamente rationale et sensuale y que es, en efecto, el subiectum signum noble sobre el cual verterá todo el discurso dantiano.

Si el signum fuera sólo rationale, no podría ser comunicado de un hombre a otro, de un emisor a un receptor. Si fuera sólo sensuale, no podría comunicar datos racionales. ${ }^{3}$

Por ser comunicado, el signo debe comprender tanto el aspecto racional como el afectivo, aunque como presentimiento todavía no bien identificado.

En suma, la co-moción que viene provocada por el signo hacia lo humano se comunica ad figuram -como en seguida veremos en nuestro Canto- en el aspecto rationale et sensuale; sólo de esta forma se realizaría, para nuestro autor, la comunicación plena del signo en el drama humano.

¿De qué aspecto tan dramático se trataría?

El tema principal del Canto en consideración es el Amor, significado del signo, en su aspecto incluso lujurioso, el que permite, por parte del poeta, una disanima -cordura-sobre su misma condición humana, en cuanto que en el otro de sí uno mismo se re-significa o se reconoce a sí mismo; en efecto, sólo dentro de un reconocimiento de unidad con

${ }^{3}$ María Corti, Percorsi dell' invenzione, 1993, Torino, Enaudi, p. 86-7. 
otro de sí, la mismidad da inicio al dinamismo de la circumincessio de sí, como ser puesto en el mundo; es decir un movimiento perenne de unidad consigo mismo y con la realidad que envuelve la circunstancia. El hombre se reconoce a sí mismo implicándose en el objeto de su mirar -theoréin - o de su conocimiento, parafraseando a San Agustín (cfr. De Trinitate), porque mirar significa adhesión de la mente: razón y corazón, al signo, objeto de amor. Y por eso para nuestro autor el amor es el que conoce: el afecto al signo -afficere-es el apego al objeto considerado, tan concreto como el clavo que se hunde en la madera.

Frente al paisaje del Infierno dantesco, a merced de la tempestad de las pasiones humanas, el poeta se encuentra extraviado en cuanto que lo que le aparece en este cuadro es finalmente un juicio sobre su misma cultura, la del amor cortés que se conjugaba con la sensualidad y a veces hasta con la impiedad.

En medio de este desconcierto se le aparecen dos almas arrastradas por la tempestad, que se le acercan juntas como palomas que apasionadamente vuelan hacia su dulce nido.

Precisamente, para no dejar pasar inobservado este hermosísimo oxímoron que se representa a través de un factor simbólico tan delicado, en un lugar en el cual le repugna cualquier sentimiento amoroso -el infierno-, mejor conviene seguir el texto: Cuali colombe dal desio chiamate/ con l'ali alzate e ferme al dolce nido/vegnon per l'aere, dal voler portate/; (igual que a palomas atraídas por el deseo y detenidas, con las alas firmes frente a su dulce nido, vienen hacia mí por el aire, llevadas por su mismo amor, / (Canto V, v. 82-84).

Las almas son las de Paolo y Francesca; ella gentil dama, que había llegado a ser famosa en los tiempos de Dante, y la de su cuñado; amantes y por esto ambos asesinados por el esposo y respectivo hermano, el príncipe, Gianciotto Malatesta. In medias res, ya desde su inicio poético, Dante no quiere dejar espacio para un juicio únicamente de tipo moral, sino para presentar una la estremecedora passio que agranda los sentimientos humanos doctrinalmente extraños al ámbito del mundo sin luz: Paolo y Francesca, todavía, son profundamente humanos. 
BRUNO GELATI

En efecto, el signum rationale et sensuale pretende presentarse bajo el símbolo de la paloma, el más tierno y apaciguador entre los seres animados: la inocente imagen del amorío perpetuo y de la entrega sensual perenne; el signo se manifiesta en el lenguaje del símbolo tradicionalmente amoroso.

Frente a esta representación, el poeta abre las puertas de su mente a un cierto sentimiento a él caro y nunca del todo abandonado en su vida, mientras presta, con asombro, oídos a las palabras púdicas y delicadas de Francesca.

Amor, ch'al cor gentil ratto s'apprende,/ prese costui de la bella persona/che mi fu tolta;/e'I modo ancor mi offende. /Amor, ch'a nullo amato amar perdona, me prese de costui piacer sí fortel che, come vedi, ancor non m'abbandona/Amor condusse/noi a una morte/Caina attende chi a vita ci spense/.

(Amor, que a quien posee el corazón gentil, rápido se apega/ atrajo a éste-Paolo-hacia mi hermosa persona/ que me ha sido quitada de tal manera que todavía el modo me ofende./

Amor que no permite -perdona-a quien sea amado no corresponderle, me raptó por el placer de éste con tal fuerza/ que, como puedes constatar todavía no me abandona./

Amor condujo a nosotros a la muerte. Caina espera a quien nos apagó la vida. cfr. v. 100-107).

\section{La justificación del amor}

Amor: éste es el punto central del encuentro dantiano. Analicemos lo que el texto sugiere al respecto.

El amor imprevisto, emblemáticamente circunstancial, envuelto en toda su naturaleza pasional y a la vez enigmática, parece solazarse entre el sentimiento puro y sus efectos mortíferos; en ello la racionalidad se abandona a una voluntad dócil, siendo que la inocencia siempre ennoblece el alma humana. 
El amor no perdona el no ser correspondido; incluso metamorfoseándose en los meandros de los placeres; uniendo la nobleza del sentimiento a la pasión carnal en lazos eternos de fidelidad hasta fundirse más y más, casi inadvertidamente, en un destino de muerte: el signo, que manifiesta y oculta al mismo tiempo, empieza a tejer su intriga, su mythos, como diría Ricoeur.

Sin embargo, estar fielmente juntos en un lugar de desesperanza, en donde el amor no debería existir, todo esto es paradójico; pero vivir esta desesperación en el lugar sin amor en compañía del amado, lo es todavía más. En el amor sensual -habría que destacar- el deseo y el signo se vuelven cómplices; en el acto amoroso, ante la presencia de la persona amada, siempre el deseo abunda en la composición del signo y lo vuelve inexorablemente sensual; y la racionalidad queda abandonada, olvidada o, al menos, distraída.

Pero Dante reclama a lo acontecido otro aspecto más dramático y ello se debe a la madurez de su razón, la que da el sentido a todo su itinerario; y por esto irrumpe en la inventio del poeta la idea de otro tipo de abundancia con respecto al deseo, en la que consiste precisamente la provocación patética central del drama: el brotar de la pietas en su interioridad, provoca el inicio de la metanoia del evento en su significado; en el relato circunstancial del adulterio de los cuñados, el poeta moldea las figuras de la trama, recreándolas según dimensiones que tendrían que ser desconocidas en el Hades; y en este instante lo humano se presenta en su misterioso e intenso actuar, sin por esto cambiar las apariencias del signo -factum infactum fieri nequit, el hecho es el hecho-, sino profundizándolas. El Infierno del poeta es el lugar en donde toda la hybris que conforma el alma humana se manifiesta para buscar un porqué que no encuentra ni en lo acontecido, ni en sí misma, ni en otro; es decir un sinsentido; incluso ni en la nostalgia; este sentimiento los dos amantes lo provocan finalmente como razonable en el alma viva, en Dante y no hacia sí mismos: la nostalgia permanece como dolor y no como respuesta (no hay mayor dolor que acordarse del tiempo feliz en la miseria...). 
BRUNO GELATI

Con la finalidad de entender estos conceptos más en profundidad, analicemos las palabras mismas de Francesca.

Su diálogo nos presenta tres componentes constantes de la tradición del ars amandi; tres justificaciones que parecen ser suficientes para sostener todo acto amoroso, aun cuando puede ser considerado ilícito.

\section{a) Amor es propio del alma gentil}

La primera imagen, la de las palomas, se pone frente a la reminiscencia del Poeta del Dolce stil novo -que sigue a la experiencia que nuestro autor vivió del amor cortés de estilo provenzal-, es decir de la poética del amor angelicato de Alighieri y sus compañeros, según los cuales Amor es propio del alma gentil; ello infunde toda nobleza al hombre como acto primigenio del espíritu. Es el amor desde el cual nacerá la misma visión angelical y su dulce plexos, inclinado de manera natural al bien del espíritu.

\section{b) Amar el amor}

74 El segundo movimiento poiético nace de la naturaleza del Amor, que siempre parece no poder admitir otra posibilidad que no sea la de corresponder al amor, es decir de amar al amor. No es un destino cruel el que primeramente se impone en la representación dantiana, sino el placer que provoca la correspondencia, por parte de quien es amado, hacia al amante; no hay en Francesca ninguna desilusión por una eventual equivocación o remordimiento por el objeto de su amor. Amor es amar; y cuando acaece tiene un solo destino: el de amar; donde, incluso, desaparecen los hipotéticos grados de sublimación del amor; hay un sólo tipo de amor y es totalidad, y en el no abandono del otro consistiría el ethos del amor.

\section{c) Amor y muerte}

La tercera figura parece ser conclusiva: la muerte; aspecto que representa la aceptación de todo riesgo: el riesgo de la propia libertad y 
que, al mismo tiempo, es para Francesca fuente de vínculo con Paolo y de reivindicación contra su esposo, quien los mató.

Ahora bien, para Dante hay una cosa más grave que romper una ley divina, natural o positiva que une a dos seres: quitar la vida al otro; y esta disposición de entrega total al otro es para nuestro autor de importancia radical, más de lo que inmediatamente se puede intuir, según lo que el poeta nos presenta al final del Canto ser el punto más dramático.

En efecto, con el interrumpirse de la existencia, según Dante, el amor no desaparece, como hermosamente nos representa en su descripción poética, sino que se elimina la posibilidad de que el amor se transhumanice: se vuelva plenamente humano, en su significado total. Es ésta una de las claves interpretativas más profundas en la poíesis de Dante: transhumanar no se puede decir con el lenguaje, porque la mente puede sólo por medio de signos y analogías decir algo sobre lo que traspasa la realidad humana (v. supra). Esto significa que sólo por medio de la significación de la experiencia humana se puede pasar de lo aparente a lo verdadero, o del valor del signo a su contenido, al porqué en sí; ello no se puede explicar sino con un contenido experiencial y siempre de forma análoga.

Impidiendo la experiencia de esta condición, que podemos definir finalmente de misterio, con una acción violenta como es el asesinato, se interrumpe el hilo conductor por el cual la circunstancia se vuelva la ocasión -en este caso para los dos amantes- de llegar al significado último del amor, que consiste en un gesto por el cual el hombre que se reconoce humillado por las leyes naturales, se remite al juego entretejido entre límite y libertad, al quis quien soportando-cum regere: corregir- en la circunstancia la experiencia del mal, devuelve en el signo del amor su último significado. Este significado pertenece para Dante finalmente al destino que, en su misteriosa intriga, puede llevar al fin último lo acontecido atrayendo a sí la libertad de las conciencias implicadas; es decir, restituir a la conciencia su propio sentido por un incógnito acto imperfecto que puede ser re-significado sólo por parte de quien puede donar satisfacción al límite que la circunstancia, expre- 


\section{BRUNO GELATI}

sada en el signo, siempre contiene: un don, una gratuidad, algo totalmente gratis.

Esta posibilidad de conciencia de amor se pone en el signo bajo la forma de pregunta original, primigenia como acto de la inteligencia que induce a una respuesta y que en la experiencia amorosa tiene un nombre: adoración. Conciencia que para Paolo y Francesca no ha sido posible vivir, en cuanto que interrumpida en su largo itinerario. En efecto, la responsabilidad, aun bajo la forma de culpa, si no se transforma en pregunta, impide la libre voluntad del hombre de recibir una respuesta exhaustiva a su por qué.

Nace entonces por parte del poeta, puesto de frente a los desafortunados amantes, el sentimiento de piedad ad figuram de compasión, la gran ausente en la psicología del Infierno. Paradójicamente, la representación de la pietas divina viene asumida entonces en este contexto por parte el poeta mismo, que se carga del pondus que el signo implica, para llevarlo a su significación (v. supra): ...oh lasso/ quanti dolci pensier, quanto disio/ menó costoro al doloroso passo/ [...] ...Francesca, i tuoi martíri/ a lagrimar mi fanno tristo e pio/ (...jo, pobre de mí/, cuántos pensamientos dulces, cuántos deseos/ condujo a ellos hacia el doloroso paso [...] ...Francesca, tus martirios/ me hacen llorar y me vuelven triste y piadoso. v. 112-117).

Dante, provocado por su misma humana naturaleza frente al drama que se está desarrollando, audazmente da el paso hacia a un pathos a imitación y participación de la pasión del ab-orante, quien no pretendiendo nada con-mueve la conciencia ontológica de su ser más allá de su natural disposición, que se abre para recibir un posible imprevisto en grado de ad venir y e-venir -ad venio et ex venio-; es decir, de acoger el sobresalto que se espera más allá de todo lo esperado. En efecto la desesperanza va de la mano con la compasión, dos movimientos, éstos, que se dirigen silentes hacia la presencia del misterio que envuelve en la dimensión temporal y espacial las circunstancias, esperando siempre una última posibilidad de cambio de sus condiciones.

Examinemos entonces la naturaleza de estas circunstancias que parecen no tener relieve y sin embargo están in speculum in enigmatae 
presentes en Francesca a través de su preguntar. Entonces desde el uso del signo, bajo la forma de alegoría -y siempre ésta aclara no sólo el aspecto especulativo, sino también el emotivo- hemos pasado al contenido mismo del signo: el amor y su justificación, según su naturaleza psicológica -afección del alma por el amor-. Además, transitamos a la fundamental disposición ontológica del alma para el amor, que encuentra su explicación en el dinamismo de la pregunta, del porqué la muerte misma, aunque lo interrumpa, según Dante, no lo elimina.

Para cerrar nuestro cerco, pasamos en fin a considerar más hondamente la relación signo-significado-circunstancias, aspecto que nos reconduce al valor pleno del signo aun cuando, como veremos, interrumpido en su unidad racional-sensual y que sólo una intervención ad extra, con respecto al acontecimiento, podrá re-significar.

\section{La interrupción de la unidad del signo y su posible recuperación}

Francesca, bajo la petición de Dante conmovido, explica cómo sucedió el apasionado enamoramiento por el cuñado.

Nessun maggior dolore/ che ricordarsi del tempo felice/ ne la miseria; e ciò sa 'l tuo dottore/. Ma s'a conoscer la prima radice/ del nostro amor tu hai cotanto affetto,/dirò come colui che piange e dice/. Noi leggiavamo un giorno per diletto/ di Lancialotto come amor lo strinse;/ soli eravamo e sanza alcun sospetto./ Per più fiate li occhi ci sospinse/ quella lettura, e scolorocci il viso;/ ma solo un punto fu quel che ci vinse./ Quando leggemmo il disiato riso/ esser basciato da cotanto amante,/ questi, che mai da me non fia diviso,/ la bocca mi basciò tutto tremante./ Galeotto fu 'I libro e chi lo scrisse:/ quel giorno più non vi leggemmo avante./ Mentre che l'uno spirto questo disse,/l'altro piangëa; sì che di pietade/ io venni men così com' io morisse./ E caddi come corpo morto cae. 
BRUNO GELATI

(No hay mayor dolor que acordarse del tiempo feliz en la miseria; y eso lo sabes bien tu Maestro. Pero si tienes tanto deseo de conocer cuál fue el principal origen de nuestro amor, haré como el que habla y llora a la vez. Leíamos un día por pasatiempo las aventuras de Lancelote, y de qué modo cayó en las redes del Amor: estábamos solos y sin abrigar sospecha alguna. Aquella lectura hizo que nuestros ojos se buscarán muchas veces y que palideciera nuestro semblante; mas un solo pasaje fue el que decidió de nosotros. Cuando leímos que la deseada sonrisa de la amada fue interrumpida por el beso del amante, éste, que jamás se ha de separar de mí, me besó tembloroso en la boca: el libro y quien lo escribió fue para nosotros otro Galeoto; aquel día ya no leímos más. Mientras que un alma decía esto, la otra lloraba de tal modo, que, movido de compasión, desfallecí como si me muriera, y caí como cae un cuerpo inanimado. v. 73-142).

El acento con el que Francesca rememora lo acaecido, no es ni de nostalgia ni de reivindicación en contra del destino cruel, sino la expresión de la retención del instante en el que la memoria se vuelve vívida -con todo el transporte del sentimiento amoroso-, porque el amor se renueva re-memorando el primer instante sucedido en la totalidad de su dimensión temporal y de lugar, que la densidad del instante siempre comprende. Éste es el momento en el cual la memoria re-memora, en cuanto que la anámnesis permite iluminar el acontecimiento y al mismo tiempo profundizar el valor del instante en el que se densifica más y más la unidad entre el signum y la conciencia del propio yo. Se trata fundamentalmente de una pertenencia nueva, de la conciencia renovada no sólo en su propio yo, sino implicada en un tú que traspasa el acontecido y abre la mente a la dimensión del misterio que se une en el signo que las circunstancias banalmente presentan: Galeoto fue el libro y quien lo escribió; la circunstancia provoca lo acaecido: desde aquel entonces ya no seguimos leyendo; y a partir de ello el drama se dispone 
a todo lo que pueda suceder; y en este contexto el imprevisto siempre presente de la muerte.

Mientras que uno de los espíritus dijo esto, el otro lloraba, porque ya no importa lo que ha sucedido mientras que siga sangrando la laceración entre el sentimiento y su último significado, fisura que permanece como dolor; lo que adquiere significado para nuestros actores será la conciencia del momento presente frente al destino que, en última instancia aun cuando dejará en una perenne unidad el amor y los amantes, lo hace permanecer en un fundamental estado de insatisfacción, siendo que su amor no ha sido jamás llenado por una respuesta última: ella deja el deseo de una cierta forma inconcluso en el signo. Por esto en esta representación el valor del signo se mengua en su naturaleza analógica -aná-, porque se quiebra la unidad de la pregunta dirigida hacia su totalidad y se coloca en un campo extraviado, en el aire del Hades, y que el misterio tal vez recoge, pero sin contestar.

En el Canto de Paolo y Francesca, signo-significado-circunstancias se unen en la memoria de un hecho que ocasionó su amor, pero que todavía no ha tenido una respuesta exhaustiva: el por qué último de lo sucedido en una condición ya última -la muerte-, en la cual la respuesta está ausente; de esta forma se rompe el drama en su unidad rationale et sensuale, condición para que el signum pueda indicar todo su sentido. La triste condición de los dos amantes no encuentra en la realidad del Infierno un descanso en el deseo de respuesta y precisamente en esto consistirá su pena. Al amor entre los dos le es impedido llegar al Amor, al sentido último de ello y por esto la circunstancia de este extravío existencial conmueve al poeta quien no tiene una respuesta sino en el ámbito del sigum que contiene el misterio explicativo de la realidad, es decir el reconocimiento de la presencia de quien sabe el por qué que nosotros ignoramos y devela, paradójicamente, la confianza en la existencia de un por qué que siempre late en la más incógnita circunstancia, en el corazón del ser.

El signo es la realidad que velando el significado permite su develación en un por qué que no se pretende, sino que se espera. Ésta, finalmente, es la actitud que el mismo signo impone, pero que en la 
BRUNO GELATI

condición de Paolo y Francesca parece ser negada. El signo permanece, según esta representación, sólo en lo sensuale, mientras que la respuesta eshaustiva al porqué se coloca en su unidad con lo rationale, porque el signo demanda la respuesta a una inteligencia que pregunta en su unidad y que, en cambio nuestro drama, viene suspendida como conciencia última de lo sucedido.

Lo sucedido se explica sólo frente al misterio que permanece detrás de los hechos. Por esto al poeta, en el final del relato de Francesca, ya no le es necesario recurrir a metáforas que pueden ser ambiguas, sino sólo a los hechos que hacen brotar en él su pietas que pregunta por una respuesta que existe, pero que no es medible por la experiencia. Existe, pero no se sabe lo que es; tal vez porque exista una dilectio amoris, como afirma $\mathrm{H}$. Arendt, [es preciso saber que] no amo simplemente a él, sino algo en él que de una forma propia no proviene de él. ${ }^{4}$

${ }^{4}$ H. Arendt, Il concetto di amore in Agostino, 1992, Milán, SEI, p. 117. 